\title{
Genetic variants in the repeat region of MHC class I for miniature pig (Brief Report)
}

\author{
Genetische Varianten von MHC Klasse I repetitiven Regionen \\ beim Miniaturschwein (Brief Report)
}

HOYOUNG CHUNG and JAEYOUNG KIM

Animal Genomics \& Bioinformatics Division, National Institute of Animal Science, Suwon, Korea

\section{Background}

Recently, miniature pigs have been issued for xenotransplantation studies (CHARON et al. 2000) to verify what major factors are critical matters for immune responses in human. Major histocompatibility complex (MHC) knowing for high rate of mutations and responsible for systematic immune responses is essential to understand swine immunology. Numerous studies have documented the influence of swine leukocyte antigen (SLA) genes on immune responses, organ and cell transplantation success and disease resistance (SMITH et al. 2004). The satellite region in MHC can be used to identify individuals as well as breeds, and it is important to characterize and breed unique miniature pig lines for supporting organ transplantation studies. Up to the present moment, genetic variants including repeat units $\left(C_{14-20}\right)$ located between the $S L A-1$ and SLA-5 genes are available with GenBank acc. no. AJ131112, AP009559, AP009558, AP009556, AP009555, and CU311184, but miniature pigs have not been reported.

\section{Procedure}

\section{Selection of primers}

To amplify the repeat region corresponding to locations from 9859 to 9892 based on BAC sequences (GenBank acc. no. AJ131112), the primers were selected at 9470-9 487 (forward) and 9 944-9 961 (reverse).

Forward primer: 5'-CAC ACG CCA GTC CTT AGA-3'

Reverse primer: 5'-GTA GCA CAG GGA ACC ATA-3'

\section{Identification of $P C R$ products}

A total of 6 families of National Institute of Health miniature pigs consisting of 6 sires mated to 14 dams producing 48 offspring were used from the National Institute of Animal Science in Korea. After collecting blood samples, individual genomic DNAs were successfully amplified with $3 \mu$ of $10 \times$ reaction buffer, $25 \mathrm{mM}$ of dNTP, $50 \mathrm{ng}$ of DNA, and 1 unit of Taq DNA polymerase in a final volume of $30 \mu$. After heating at $95^{\circ} \mathrm{C}$ for $3 \mathrm{~min}$, a total of 35 cycles was adapted for denaturation at $94^{\circ} \mathrm{C} / 1 \mathrm{~min}$, annealing at $52^{\circ} \mathrm{C} / 1 \mathrm{~min}$, and polymerization at $72^{\circ} \mathrm{C} / 1.5 \mathrm{~min}$. The PCR products were inserted into $\mathrm{PGEM} \mathrm{T}$ easy vector, and 5 clones per animal were sequenced with Big-dye terminator version 3.1. 


\section{Results}

The amplification produced a fragment approximate $492 \mathrm{bp}$ that has been submitted into GenBank with an accession number (EU547237). After alignment of all individual sequences with the Seqman program of DNAstar version 6.1, we observed $C A_{13}, C A_{15}$, and $C A_{20}$ repeat units positioned from 400 to 425 , and the repeat units $\left(C A_{13}\right.$ and $\left.C A_{15}\right)$ in this study are the first report. Mendelian inheritance was confirmed by 6 families and allele frequencies were estimated for $C A_{13}$ (0.131), $C A_{15}$ (0.407), and $C A_{20}$ (0.461) units. According to the SLA-5 haplotypes, the repeat units may be significantly associated with determining haplotypes that contained specific repeat units even though some of the sequences have not been determined for haplotypes (Figure 1). Sequence comparison also revealed 7 single nucleotide polymorphisms (SNP) positioned at 55 (T/G), 97 (G/A), $166(\mathrm{C} / \mathrm{T}), 181(\mathrm{~T} / \mathrm{C}), 240(\mathrm{~T} / \mathrm{C}), 324(\mathrm{~T} / \mathrm{C})$, and $350(\mathrm{G} / \mathrm{T})$ based on the identified sequence (EU547237). We also found an insertion of $G$ between positions 229 and 230 and 10 bp of deletion (GTTGT TTTTG) between positions 292 to 303 showing in only miniature pigs. However, the SNPs including the insertion and deletion may not be related to determining haplotypes. Therefore, the identified repeat units may be used to specify SLA-5 haplotypes as well as individual genotypes, and we believe that these findings may be useful to identify and characterize miniature pigs regarding xenotransplantation researches.

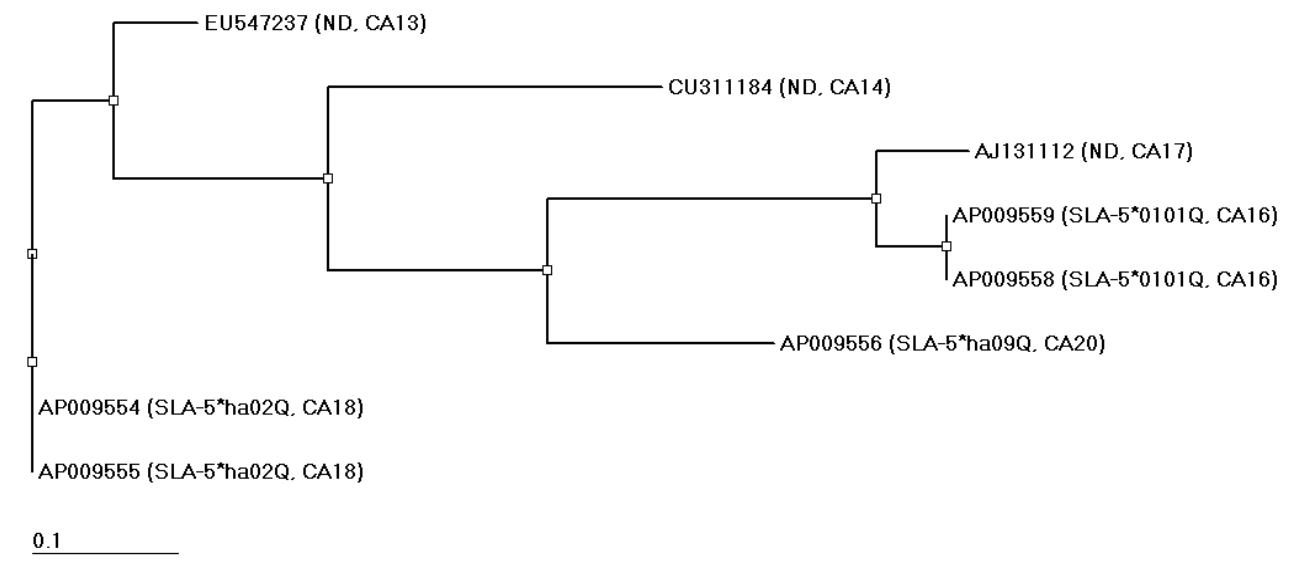

Figure 1

Genetic distances among sequences contained repeat regions that located in $5^{\prime}$ of the swine $S L A-5$ gene. The phylogenic tree was constructed with DNADist in Bioedit program version 7.0.1. GenBank accession numbers, SLA- 5 allele names, and repeat units of the represented sequences are shown. ND stands for not determined.

Genetische Distanzen von Sequenzen mit repetitiven Abschnitten $5^{\prime}$ des porcinen SLA-\% Gens. Der phylogenetische Baum wurde mit DNADist in Bioedit Version 7.0.1 erstellt. GenBank Accession-Nummern, die SLA-5-Allelnamen und die repetiven Regionen der dargestellten Sequenzen sind angegeben. ND bedeutet »nicht bestimmt".

\section{Acknowledgements}

This research has been supported by grants from Biogreen 21 program (2007040103402901). 


\section{References}

Charon P, Renard C, Gaillard CR, Vaiman M (2000) The porcine major histocompatibility complex and related paralogous regions: a review. Gen Sel Evol 32, 109-28

Smith DM, Lunney JK, Martens GW, Ando A, Lee JH, Ho CS, Schook L, Reneard C, Chardon P (2004) Nomenclature for factors of the SLA class-I system. Tissue Antigens 65, 136-49

Received 14 March 2008, accepted 14 May 2009.

Corresponding author:

Dr. HOYOUNG CHUNG

email: chung133@rda.go.kr

Animal Genomics \& Bioinformatics Division, National Institute of Animal Science, Suwon 441-701, Korea 